\title{
Metabolite Profile of Lactic Acid-Fermented Soymilk
}

\author{
Maki Kobayashi' ${ }^{1}$, Tomoyo Shima ${ }^{2}$, Mitsuru Fukuda ${ }^{3}$ \\ ${ }^{1}$ Department of Nutrition, School of Nutrition, Kobegakuin University, Kobe, Japan \\ ${ }^{2}$ Research Institute, Marusan-Ai Co., Ltd., Okazaki, Japan \\ ${ }^{3}$ Research Institute for Nutrition Sciences, Mukogawa Women's University, Nishinomiya, Japan \\ Email: *kobayashi@nutr.kobegakuin.ac.jp, tomoyo.shima@marusanai.co.jp, senjuoka@mukogawa-u.ac.jp
}

How to cite this paper: Kobayashi, M. Shima, T. and Fukuda, M. (2018) Metabolite Profile of Lactic Acid-Fermented Soymilk. Food and Nutrition Sciences, 9, 1327-1340. https://doi.org/10.4236/fns.2018.911095

Received: October 19, 2018

Accepted: November 25, 2018

Published: November 28, 2018

Copyright $\odot 2018$ by authors and Scientific Research Publishing Inc. This work is licensed under the Creative Commons Attribution International License (CC BY 4.0).

http://creativecommons.org/licenses/by/4.0/

\begin{abstract}
Isoflavone aglycone-rich soymilk fermented by Lactobacillus delbrueckii subsp. delbrueckii, strain TUA-4408L (F4408) has stronger lipid metabolism-modulating effects than isoflavone aglycone-poor soymilk fermented by Lactobacillus delbrueckii subsp. delbrueckii, strain TUA-4404L (F4404). As such, fermentation products other than isoflavone aglycones may also exert lipid metabolism-modulating effects. Therefore, the present study aimed to compare the metabolites in soymilk (SM), F4404, and F4408 via a metabolomics approach. Various aglycones including isoflavones, flavones, flavonols, and flavanones increased in both F4404 and F4408 compared with SM. The increases in isoflavone and flavanone aglycones were greater in F4408 than in F4404. Some types of dipeptides and free amino acids, especially ornithine, increased in both fermented soymilks. The increase in free amino acids, especially ornithine, was higher in F4408 than in F4404. Thus, F4408 exhibited stronger glycosidase and protease activities than F4404. Functional components produced by lactic acid fermentation are known to improve lipid metabolism. Therefore, it is suggested that not only isoflavone aglycones but also other functional components exert lipid metabolism-modulating effects in fermented soymilks, especially soymilk fermented using TUA-4408L.
\end{abstract}

\section{Keywords}

Fermented Soymilk, Metabolite, Polyphenol Aglycone, Ornithine

\section{Introduction}

Traditional soy foods produced in Asia are known to have lipid metabolism-modulating effects [1]. Soy protein and isoflavones are the major bioactive 
components in soy foods. Soy protein reduces cholesterol levels by inhibiting cholesterol absorption in the intestines and promoting fecal excretion through bile acid binding [2] [3] [4] [5]. Furthermore, soy protein also reduces plasma triglyceride levels and body fat mass [6]. In addition, isoflavones are known to be effective against obesity [7] and reduce adipose deposition in a dose-dependent manner [8]. Moreover, isoflavones have been found to modulate hepatic glucose and lipid metabolism [9] [10]. Clinical analyses and meta-analyses have demonstrated the lipid metabolism-modulating effects of combined isoflavones and soy protein [11] [12] [13] [14]. Although soymilk is the simplest soy food, some individuals find the flavor unpalatable. Thus, we used soymilk fermented by lactic acid bacteria of vegetable origin to make its flavor more palatable. Lactic acid fermentation converts the isoflavone glycosides in soymilk to isoflavone aglycones [15], enhancing their absorption in the intestine [16]. We previously reported the lipid metabolism-modulating effects of fermented soymilk in rats fed an AIN-93G diet [17], a high-cholesterol diet [18], a high-fat diet [19], and a high-fat and high-cholesterol diet [20] [21]. Our results indicated that an increase in the amount of isoflavone aglycones in fermented soymilk enhanced its lipid metabolism-modulating effects [21].

Although our previous results indicated that the administration of only the isoflavone aglycone fraction from fermented soymilk did not improve lipid metabolism in rats fed a high-cholesterol diet, lipid metabolism improved when the isoflavone aglycone fraction was administered with soy protein [22]. Moreover, it was found that the isoflavone fraction used in our pervious study, ethanol extract from fermented soymilk, contained both isoflavone aglycones and soy peptides [22]. The fermented soymilk protein-derived peptide fraction containing isoflavone aglycones also improved lipid metabolism in HepG2 cells [23]. In our previous study, when we compared the physiological effects of fermented soymilk containing a high ratio of isoflavone aglycone (prepared using Lactobacillus delbrueckii subsp. delbrueckii TUA-4408L) with those of fermented soymilk containing a low ratio of isoflavone aglycone (prepared using Lactobacillus delbrueckii subsp. delbrueckii TUA-4404L), we found that an increase in isoflavone aglycones in fermented soymilk enhanced its lipid metabolism-modulating effect [21], suggesting that fermentation products other than isoflavone aglycone may be responsible for these effects. Therefore, the present study aimed to analyze the metabolites of soymilk, fermented soymilk prepared using Lactobacillus delbrueckii subsp. delbrueckii, strains TUA-4404L and TUA-4408L via a metabolomics approach.

\section{Materials and Methods}

\subsection{Preparation of Soymilk and Fermented Soymilk}

Commercially available soymilk was obtained from Marusan-Ai Co., Ltd. (Okazaki, Japan). Two fermented soymilk products were prepared from soymilk via lactic acid fermentation for $15 \mathrm{~h}$ using Lactobacillus delbrueckii subsp. delbru- 
eckii, strain TUA-4404L (F4404) or TUA-4408L (F4408).

\subsection{Mass Spectrometry and Liquid Chromatography for Metabolomics Analysis}

The soymilk metabolome analyses were carried out at Human Metabolome Technologies Inc. (HMT, Tsuruoka, Japan). One hundred $\mu$ l of SM, F4404, or F4408, and $900 \mu \mathrm{L}$ of methanol containing $10 \mu \mathrm{M}$ internal standard, $1 \mathrm{~mL}$ of chloroform, and $400 \mu \mathrm{L}$ of Milli-Q water were mixed for capillary electrophoresis time-of-flight mass spectrometry (CE-TOFMS). The mixtures were centrifuged for $5 \mathrm{~min}$ at $2300 \times \mathrm{g}$ at $4^{\circ} \mathrm{C}$. The aqueous phase was passed through an ultrafiltration membrane ( $5 \mathrm{kDa}$ cutoff filter; Ultrafree MC, HMT) for $120 \mathrm{~min}$ at $9100 \times g$ at $4^{\circ} \mathrm{C}$. The flowthrough fraction was completely evaporated, and the residue was dissolved in $50 \mu \mathrm{L}$ of Milli-Q water. The flowthrough fraction was diluted 2-fold Milli-Q water for cationic metabolites analysis or 5-fold with Milli-Q water for anionic metabolite analysis.

CE-TOFMS was carried out using an Agilent CE Capillary Electrophoresis System. Cationic metabolites were analyzed using a fused cilia capillary tube (50 $\mu \mathrm{m} \times 80 \mathrm{~cm})$, with cation electrophoresis buffer (H3301-1001, HMT) as the electrolyte. The sample was injected at a pressure of $50 \mathrm{mbar}$ for $10 \mathrm{~s}$, and the applied voltage was set at $27 \mathrm{kV}$. Electrospray ionization mass spectrometry (ESI-MS) was conducted in positive ion mode, the capillary voltage was set at $4000 \mathrm{~V}$, and the spectrum was scanned from m/z 50 to 1000 . Anionic metabolites were analyzed with a fused silica capillary tube, with anionic electrophoresis buffer (H3302-1021, HMT) as the electrolyte. The sample was injected at a pressure of 50 mbar for $25 \mathrm{~s}$, and the applied voltage was set at $30 \mathrm{kV}$. ESI-MS was conducted in negative ion mode, the capillary voltage was set at $3500 \mathrm{~V}$, and the spectrum was scanned from $\mathrm{m} / \mathrm{z} 50$ to 1000 .

Five hundred $\mu \mathrm{l}$ of SM, F4404, or F4408, and $1500 \mu \mathrm{L}$ of $1 \%$ formic acid-acetonitrile containing $6 \mu \mathrm{M}$ internal standards were mixed for liquid chromatography-time-of-flight mass spectrometry (LC-TOFMS), and the mixture was centrifuged for $5 \mathrm{~min}$ at $2300 \times g$ at $4^{\circ} \mathrm{C}$. The supernatant was dried and dissolved in $100 \mu \mathrm{L}$ of $50 \%$ isopropanol.

LC-TOFMS was carried out using an Agilent 1200 series RRLC System SL equipped with an Agilent LC/MSD TOF (Agilent Technologies). The system was run in gradient mode at $40^{\circ} \mathrm{C}$ using an octadecylsilyl column $(2 \mu \mathrm{m}, 2 \times 50 \mathrm{~mm})$. Solvent A consisted of $\mathrm{H}_{2} \mathrm{O}$ containing $0.1 \%$ formic acid, and solvent $\mathrm{B}$ consisted of isopropanol containing $0.1 \%$ formic acid and $2 \mathrm{mM}$ ammonium hydrogen carbonate, acetonitrile, and $\mathrm{H}_{2} \mathrm{O}(65: 30: 5)$. The flow rate was set at $0.3 \mathrm{~mL} / \mathrm{min}$, and the gradient was set as follows: $1 \% \mathrm{~B}$ (from 0 to $0.5 \mathrm{~min}$ ), linearly increasing to $100 \% \mathrm{~B}$ (from 0.5 to $13.5 \mathrm{~min}$ ), and holding at $100 \% \mathrm{~B}$ (from 13.5 to $20 \mathrm{~min}$ ).

MS analysis was carried out in both positive and negative ion ESI modes of detection. The operating parameters were as follows: drying gas $\left(\mathrm{N}_{2}\right)$ flow rate, $10 \mathrm{~L} / \mathrm{min}$; drying gas temperature, $350^{\circ} \mathrm{C}$; nebulizer pressure, $40 \mathrm{psi}$; capillary voltage, $3500 \mathrm{~V}$; and mass scanning range, m/z 100 - 1700. Metabolome raw data 
were processed using Master Hands ver. 2.17.1. The metabolites and peptides (two to four amino acid residues) were annotated using the metabolite library and peptide list maintained by HMT, respectively.

\section{Results and Discussion}

\subsection{Differences between the Metabolic Profiles of Soymilk and Fermented Soymilk Products}

Metabolome analysis was performed on the CE-TOFMS and LC-TOFMS data for SM, F4404, and F4408. CE-TOFMS detected 347 peaks in the samples (270 cation peaks and 77 anion peaks). Additionally, quantitative values were calculated for 71 of the detected substance peaks ( 43 cation and 28 anion peaks). LC-TOFMS detected 119 peaks in the samples (60 positive peaks and 59 negative peaks). The $\mathrm{m} / \mathrm{z}$ and migration time or retention time values of 361 peaks were used to identify these substances as candidate compounds using the HMT metabolite library and Known-Unknown library Candidate. Furthermore, an additional 105 peaks were identified as candidate compounds when peak $\mathrm{m} / \mathrm{z}$ values were compared with the HMT peptide list (two to four residues).

\subsection{Changes in Identified Metabolite Quantities through Fermentation}

\subsubsection{Isoflavone Aglycones}

It is well known that genistein (an isoflavone aglycone) has lipid metabolism-modulating effects [8] [9] [10], and lactic acid-fermented soymilk is reportedly rich in genistein [21] [22] [23]. In addition, it is reported that baicalein (a flavone aglycone) inhibits fat accumulation [24]. The amount of genistein or baicalein was 1.4-fold higher in F4404 and 7.3-fold higher in F4408 than in SM (Table 1). Because genistein and baicalein have the same molecular weight, this metabolome analysis was unable to identify which substance was present in each of the soymilk products. Thus, it is assumed that either genistein or baicalein may contribute to the lipid metabolism-modulating effects of lactic acid-fermented soymilk.

Soy reportedly contains only a small amount of glycitein (an isoflavone aglycone) [25]. In the present study, the amount of glycitein was 2.1-fold higher in F4404 and 16-fold higher in F4408 than in SM (Table 1). Additionally, formononetin

Table 1. Isoflavone aglycones in F4404 and F4408 compared with SM.

\begin{tabular}{cccc}
\hline \multirow{2}{*}{ Group } & & \multicolumn{2}{c}{ Comparative Analysis } \\
\cline { 3 - 4 } & Compound name & \multicolumn{2}{c}{ Ratio } \\
\cline { 3 - 4 } Isoflavone & Genistein & 1.4 & F4408 vs. SM \\
& Baicalein & & 7.3 \\
& Glycitein & 2.1 & 16 \\
& Formononetin & 1.1 & 5.3 \\
\hline
\end{tabular}


(2,4'-O-methylated daidzein, an isoflavone aglycone) was unchanged in F4404 but was 5.3-fold higher in F4408 than in SM (Table 1). It has been reported that formononetin affects lipid and protein metabolism in the liver of ovariectomized rats [26], as well as their estrogenic function [27]. Therefore, it is suggested that these isoflavones influence the lipid metabolism-modulating effect of lactic acid-fermented soymilk.

\subsubsection{Flavones or Flavonols}

Luteolin improves obesity and insulin resistance [28]. Datiscetin reportedly has a preventive effect against Alzheimer's type dementia [29]. Kaempferol glycoside has anti-obesity and anti-diabetic effects [30]; thus, kaempferol aglycone may provide stronger effects than kaempferol glycoside. Additionally, isoorientin (a glycoside of luteolin) prevents hyperlipidemia and liver injury by regulating lipid metabolism, antioxidant capability, and inflammatory cytokine release in high-fructose-fed mice [31]. The amount of luteolin, datiscetin, or kaempferol did not change in F4404, but it increased significantly in F4408 compared with SM (Table 2). Because luteorin, datiscetin, and kaempferol have the same molecular weight, it was not possible to identify which substance was present in this metabolome analysis. Therefore, it was suggested that lipid metabolism-modulating effects may be promoted by increasing any one of these lactic acid fermentation-derived substances. As isoorientin or luteolin 7-glucoside decreased in F4408 compare with that in F4404, luteorin seems to be the most possible substance in F4408.

Quercetin-3-rutinoside (Rutin) is reported to be effective in regulating blood biochemical parameters in hamsters with hypercholesterolemia [32]. Because F4408 has the ability to convert glycosides to aglycones, the value was higher in F4408 than in F4404 as compared with that in SM (Table 2). Saponarin (a polyphenol glycoside), which has a protective effect on the liver [33], was 19-fold higher in F4404 and 9.8-fold higher in F4408 than in SM (Table 2). Apigenin is known to activate PPAR $\gamma$ [34] and has a suppressing effect on the expression of NAFLD by improving oxidative stress and improving abnormality hepatic lipid

Table 2. Flavones or flavonols in F4404 and F4408 compared with SM.

\begin{tabular}{cccc}
\hline \multirow{2}{*}{ Group } & Compound name & \multicolumn{2}{c}{ Comparative Analysis } \\
\cline { 3 - 4 } & & \multicolumn{2}{c}{ Ratio } \\
\cline { 3 - 4 } & Luteolin & F4404 vs. SM & F4408 vs. SM \\
Datiscetin & $<1$ & 8.6 \\
Klavone or & Kaempferol & & 1.7 \\
Isoorientin & Luteolin 7-glucoside & 9.8 & 3.2 \\
& Quercetin 3-rutinoside & 1.8 & 9.8 \\
& Saponarin & 19 & 1.8 \\
\hline
\end{tabular}


metabolism [35]. Apigenin-7 glucosides increased in F4404 and F4408 compared with SM (Table 2). Therefore, it was suggested that apigenin was produced from apigenin glucoside in fermented soymilks and may influence the lipid metabolism-modulating effect of lactic acid-fermented soymilk.

\subsubsection{Flavanones in F4404 and F4408}

Naringenin (a flavanone aglycone) was 3.6-fold higher in F4404 and 8.8-fold higher in F4408 than in SM (Table 3). Naringin (a naringenin glycoside) is known to improve hyperlipidemia and lipid metabolism [36], to decrease blood cholesterol levels, and to have antioxidant effect [37] [38]. As aglycones have greater effect of lipid metabolism-modulating effects than glycosides, naringenin is expected to have greater effects on lipid metabolism than naringin.

Eriocitrin is known to improve fatty liver [39]. Eriodictyol-7-neohesperidoside is a substance that has not been extensively studied, and its effect on lipid metabolism is therefore unknown. The amount of eriocitrin was unchanged in F4404 and F4408 compared with SM (Table 3).

Liquiritigenin inhibits LXR-dependent steatosis and oxidative damage [40]. Isoliquiritigenin has been reported to protect against alcohol-induced fatty liver by regulating the SIRT-1-AMPK pathway and to inhibit LXRa-dependent steatosis [41] [42]. In the present study, levels of isoliquiritigenin were higher in F4408 than in F4404 as compared with SM (Table 3). Therefore, it was suggested that these compounds may play a role in the lipid metabolism-modulating effects of lactic acid-fermented soymilk.

\subsubsection{Dipeptides}

Some dipeptides increased in fermented soymilks compared with those found in SM. There was not a great difference in the production of dipeptides in F4408 and F4404, with a few exceptions (Table 4). Asp-Asp increased in F4408 compared with SM. Ala-Ser or Thr-Gly increased in F4404 and F4408 compared with SM (Table 4). Although fermentation did not remarkably increase the amount of oligopeptides [23], only Ala-Ala or daminozide is dramatically increased in F4404 and F4408 compared with SM (Table 4). Production of new peptides demonstrates the increase in protease and peptidase activities during fermentation.

Table 3. Flavanones in F4404 and F4408 compared with SM.

\begin{tabular}{|c|c|c|c|}
\hline \multirow{3}{*}{ Group } & \multirow{3}{*}{ Compound name } & \multicolumn{2}{|c|}{ Comparative Analysis } \\
\hline & & \multicolumn{2}{|c|}{ Ratio } \\
\hline & & F4404 vs. SM & F4408 vs. SM \\
\hline \multirow{4}{*}{ Flavanone } & Naringenin & 3.6 & 8.8 \\
\hline & $\begin{array}{c}\text { Eriocitrin } \\
\text { Eriodictyol 7-neohesperidoside }\end{array}$ & 2.2 & 1.8 \\
\hline & Liquiritigenin & 1.5 & 3.2 \\
\hline & Isoliquiritigenin & 0.6 & 3.3 \\
\hline
\end{tabular}


Table 4. Dipeptides in F4404 and F4408 compared with SM.

\begin{tabular}{|c|c|c|}
\hline \multirow{3}{*}{ Estimated peptide } & \multicolumn{2}{|c|}{ Comparative Analysis } \\
\hline & \multicolumn{2}{|c|}{ Ratio } \\
\hline & F4404 vs. SM & F4408 vs. SM \\
\hline $\begin{array}{l}\text { Ala-Ser } \\
\text { Thr-Gly }\end{array}$ & 3.5 & 3.4 \\
\hline $\begin{array}{l}\text { Ala-Thr } \\
\text { Thr-Ala }\end{array}$ & $<1$ & $<1$ \\
\hline $\begin{array}{l}\text { Arg-Glu } \\
\text { Glu-Arg }\end{array}$ & $<1$ & $<1$ \\
\hline $\begin{array}{l}\text { Arg-Gly } \\
\text { Gly-Arg }\end{array}$ & $<1$ & $<1$ \\
\hline Arg-Pro & $<1$ & $<1$ \\
\hline $\begin{array}{l}\text { Asn-Asp } \\
\text { Asp-Asn }\end{array}$ & 1.1 & 1.8 \\
\hline $\begin{array}{l}\text { Asn-Ile } \\
\text { Asn-Leu } \\
\text { Ile-Asn } \\
\text { Leu-Asn } \\
\text { Val-Gln }\end{array}$ & N.A. & $1<$ \\
\hline $\begin{array}{l}\text { Asn-Thr } \\
\text { Ser-Gln } \\
\text { Thr-Asn }\end{array}$ & $<1$ & $<1$ \\
\hline Asp-Arg & 1.2 & 1.3 \\
\hline Asp-Asp & $<1$ & 4.2 \\
\hline Asp-Glu & $<1$ & 1.4 \\
\hline Asp-Gly & 0.7 & 0.8 \\
\hline Asp-Lys & 0.9 & 1.1 \\
\hline $\begin{array}{l}\text { Asp-Ser } \\
\text { Ser-Asp }\end{array}$ & $<1$ & $<1$ \\
\hline $\begin{array}{c}\text { Daminozide } \\
\text { Ala-Ala }\end{array}$ & 22 & 15 \\
\hline Glu-Asp & $<1$ & 1.1 \\
\hline Glu-Glu & $<1$ & 0.5 \\
\hline Glu-Ser & $<1$ & 0.7 \\
\hline Gly-Asp & $<1$ & 1.0 \\
\hline Gly-Gly & N.A. & $1<$ \\
\hline $\begin{array}{l}\text { Gly-His } \\
\text { His-Gly }\end{array}$ & $<1$ & $<1$ \\
\hline $\begin{array}{l}\text { Gly-Lys } \\
\text { Lys-Gly }\end{array}$ & $<1$ & 0.9 \\
\hline $\begin{array}{l}\text { Ile-Ala } \\
\text { Leu-Ala }\end{array}$ & N.A. & $1<$ \\
\hline $\begin{array}{l}\text { Ile-Lys } \\
\text { Lys-Ile } \\
\text { Lys-Leu } \\
\text { Leu-Lys }\end{array}$ & $<1$ & 0.5 \\
\hline
\end{tabular}




\begin{tabular}{ccc}
\hline Leu-Ile & N.A. & $1<$ \\
Leu-Leu & N.A. & $1<$ \\
Leu-Phe & $<1$ & 0.4 \\
Lys-Asp & $<1$ & $<1$ \\
Lys-Ser & N.A. & $1<$ \\
Ser-Lys & 1.1 & 1.1 \\
Phe-Asn & & \\
Phe-Thr & $<1$ & $<1$ \\
Thr-Asp & & \\
Asp-Thr & $<1$ & $<1$ \\
Ser-Glu & $<1$ & $<1$ \\
Val-Glu & $<1$ & 0.4 \\
Val-Lys & $<1$ & 0.7 \\
$\gamma$-Glu-2-aminobutyric acid & & \\
$\gamma$-Glu-Val-Gly & &
\end{tabular}

N.D.: Not Detected. N.A.: Not Available.

\subsubsection{Free Amino Acids}

Free amino acids in fermented soymilk were produced by degradation of soy protein by Lactobacillus delbrueckii subsp. delbrueckii, strain TUA-4404L or TUA-4408L (Table 5). Glutamine, tyrosine, $\beta$-alanine, homoserine, and citrulline were more abundant in F4404 than in SM or F4408, but other amino acids were more abundant in F4408 than in SM or F4404 (Table 5). Ornithine is produced from arginine [43], and it is noteworthy that arginine decreased in F4404 and F4408, whereas ornithine drastically increased (Table 5). In particular, the ornithine content of F4408 was 429-fold higher than that of SM (Table 5). Lactobacillus delbrueckii subsp. delbrueckii strain TUA-4408L has stronger metabolic activity than TUA-4404L (Table 5). It was revealed that TUA-4408L has a greater ability to convert arginine to ornithine. Ornithine is metabolized to citrulline, but the amount of citrulline in F4408 is lower than in F4404 (Table 5). As ornithine has been reported to improving lipid metabolism [44] [45]. It was suggested that the ornithine in F4408 may influence its lipid metabolism-modulating effect. Additionally, proline, which promotes collagen synthesis, is also produced from ornithine [46]. Because F4408 contains an abundance of ornithine, it is thought that proline and hydroxyproline also increased in F4408 compared with SM (Table 5).

\subsubsection{Polyamines}

Polyamines exhibit anti-aging properties [47] [48]. Polyamines increased in F4404 and F4408 (Table 6) compared with SM. The ratios of polyamine in F4404 and F4408 compared with SM were nearly equal. In addition, ornithine, which is a precursor of polyamine, increased markedly through lactic acid fermentation (see section 3.2.5). 
Table 5. Free amino acids in F4404 and F4408 compared with SM.

\begin{tabular}{|c|c|c|c|c|c|}
\hline \multirow{3}{*}{ Compound name } & \multirow{2}{*}{\multicolumn{3}{|c|}{ Concentration $(\mu \mathrm{M})$}} & \multirow{2}{*}{\multicolumn{2}{|c|}{$\begin{array}{c}\text { Comparative Analysis } \\
\text { Ratio }\end{array}$}} \\
\hline & & & & & \\
\hline & SM & F4404 & F4408 & F4404 vs. SM & F4408 vs. SM \\
\hline Glycine & 85 & 109 & 306 & 1.3 & 3.6 \\
\hline Alanine & 235 & 167 & 360 & 0.7 & 1.5 \\
\hline Serine & 45 & 103 & 416 & 2.3 & 9.2 \\
\hline Threonine & 19 & 40 & 174 & 2.1 & 8.9 \\
\hline Asparagine & 98 & 14 & 91 & 0.15 & 0.9 \\
\hline Glutamine & 2.6 & 17 & 2.0 & 6.6 & 0.8 \\
\hline Aspartic acid & 208 & 81 & 722 & 0.4 & 3.5 \\
\hline Glutamic acid & 423 & 240 & 1,437 & 0.6 & 3.4 \\
\hline Lysine & 42 & 42 & 423 & 1.0 & 10 \\
\hline Arginine & 379 & 272 & 0.8 & 0.7 & 0.002 \\
\hline Histidine & 50 & 55 & 168 & 1.1 & 3.3 \\
\hline Valine & 48 & 23 & 299 & 0.5 & 6.2 \\
\hline Leucine & 46 & 28 & 184 & 0.6 & 4.0 \\
\hline Isoleucine & 37 & 9.9 & 156 & 0.3 & 4.3 \\
\hline Tyrosine & 20 & 40 & 30 & 2.0 & 1.5 \\
\hline Phenylalanine & 40 & 92 & 112 & 2.3 & 2.8 \\
\hline Tryptophan & 147 & 43 & 124 & 0.3 & 0.8 \\
\hline Proline & 45 & 123 & 340 & 2.7 & 7.5 \\
\hline Methionine & 20 & 1.0 & 26 & 0.05 & 1.3 \\
\hline Cysteine & 0.4 & 0.2 & 2.1 & 0.4 & 5.1 \\
\hline$\beta$-Alanine & 57 & 127 & 84 & 2.2 & 1.5 \\
\hline Homoserine & 2.3 & 9.8 & N.D. & 4.3 & $<1$ \\
\hline Hydroxyproline & 3.2 & 4.7 & 4.7 & 1.5 & 1.5 \\
\hline Ornithine & 1.4 & 102 & 620 & 71 & 429 \\
\hline Citrulline & 9.9 & 202 & 74 & 20 & 7.5 \\
\hline
\end{tabular}

Table 6. Polyamines in F4404 and F4408 compared with SM.

\begin{tabular}{ccc}
\hline & \multicolumn{3}{c}{ Comparative Analysis } \\
\cline { 2 - 3 } Compound name & \multicolumn{2}{c}{ Ratio } \\
\cline { 2 - 3 } & F4404 vs. SM & F4408 vs. SM \\
\cline { 2 - 3 } Agmatine & 5.2 & 4.8 \\
Cadaverine & 4.1 & 3.5 \\
$N$-Acetylputrescine & 12 & 14 \\
$N^{8}$-Acetylspermidine & 4.4 & 2.5 \\
Putrescine & 5.2 & 5.0 \\
Spermidine & 6.4 & 7.1 \\
Spermine & $1<$ & $1<$ \\
\hline
\end{tabular}


Table 7. Organic acids in F4404 and F4408 compared with SM.

\begin{tabular}{cccccc}
\hline \multirow{2}{*}{$\begin{array}{c}\text { Compound } \\
\text { name }\end{array}$} & \multicolumn{3}{c}{ Concentration $(\mu \mathrm{M})$} & \multicolumn{2}{c}{ Comparative Analysis } \\
\cline { 2 - 6 } & SM & F4404 & F4408 & F4404 vs. SM & F4408 vs. SM \\
\hline Lactic acid & 59 & 94,722 & 90,406 & 1619 & 1545 \\
Succinic acid & 58 & 1764 & 2413 & 30 & 42 \\
Malic acid & 1207 & 35 & 35 & 0.03 & 0.03 \\
\hline
\end{tabular}

\subsubsection{Organic Acids}

Fermented soymilk was prepared via lactic acid fermentation using Lactobacillus delbrueckii subsp. delbrueckii, strains TUA-4404L or TUA-4408L. Thus, the amount of lactic acid increased remarkably in F4404 and F4408 (Table 7). It is also known that lactic acid bacteria, including those used in the present study, convert malic acid to lactic acid [49], as can be seen in Table 7. In addition, it was revealed that these two strains of lactic acid bacteria, especially strain TUA-4408, have a high capacity to produce succinic acid, a flavor ingredient [50]. It is therefore possible that F4408 is more palatable than F4404 (Table 7).

\section{Conclusion}

Various aglycones including isoflavones, flavones, flavonols, and flavanones increased in the two types of lactic acid-fermented soymilk prepared using Lactobacillus delbrueckii subsp. delbrueckii, strains TUA-4408L (F4408) and TUA-4404L (F4404) compared with the original soymilk. The increases in isoflavone and flavanone aglycones were greater in F4408 than in F4404. Our results indicate that Lactobacillus delbrueckii subsp. delbrueckii, strain TUA-4408L has the ability to effectively convert polyphenol glycosides to aglycones. Although the amounts of oligopeptides were not changed by lactic acid fermentation, the amounts of some dipeptides and free amino acids increased in both fermented soymilks. Additionally, our results indicate that F4408 has stronger protease activity than F4404, and the amount of ornithine dramatically increased in F4408. These functional components are known to improve lipid metabolism. Polyamines and succinic acid also increased in both fermented soymilks. Therefore, it is suggested that not only isoflavone aglycone but also other functional components exert lipid metabolism-modulating effects in fermented soymilks, especially F4408.

\section{Acknowledgements}

This research was supported by JSPS KAKENHI Grant Number 26750028 and $18 \mathrm{~K} 11061$.

\section{Conflicts of Interest}

The authors declare no conflicts of interest regarding the publication of this paper. 


\section{References}

[1] Sirtori, C.R., Lovati, M.R., Manzoni, C., Monetti, M., Pazzucconi, F. and Gatti, E. (1995) Soy and Cholesterol Reduction: Clinical Experience. Journal of Nutrition, $125,598 \mathrm{~S}-605 \mathrm{~S}$.

[2] Meeker, D.R. and Kesten, H.D. (1940) Experimental Atherosclerosis and High Protein Diets. Experimental Biology and Medicine, 45, 543-545.

https://doi.org/10.3181/00379727-45-11744P

[3] Nagata, Y., Ishiwaki, N. and Sugano, M. (1982) Studies on the Mechanism of Antihypercholesterolemic Action of Soy Protein and Soy Protein-Type Amino Acid Mixtures in Relation to the Casein Counterparts in Rats. Journal of Nutrition, 112, 1614-1625. https://doi.org/10.1093/jn/112.8.1614

[4] Yashiro, A., Oda, S. and Sugano, M. (1985) Hypocholesterolemic Effect of Soybean Protein in Rats and Mice after Peptic Digestion. Journal of Nutrition, 115, 1325-1336. https://doi.org/10.1093/jn/115.10.1325

[5] Carroll, K.K. (1991) Review of Clinical Studies on Cholesterol-Lowering Response to Soy Protein. Journal of the American Dietetic Association, 91, 820-827.

[6] Jenkins, D.J., Mirrahimi, A., Srichaikul, K., Berryman, C.E., Wang, L., Carleton, A., Abdulnour, S., Sievenpiper, J.L., Kendall, C.W. and Kris-Etherton, P.M. (2010) Soy Protein Reduces Serum Cholesterol by Both Intrinsic and Food Displacement Mechanisms. Journal of Nutrition, 140, 2302S-2311S.

https://doi.org/10.3945/jn.110.124958

[7] Ørgaard, A. and Jensen, L. (2008) The Effects of Soy Isoflavones on Obesity. Experimental Biology and Medicine, 233, 1066-1080. https://doi.org/10.3181/0712-MR-347

[8] Penza, M., Montani, C., Romani, A., Vignolini, P., Pampaloni, B., Tanini, A., Brandi, M.L., Alonso-Magdalena, P., Nadal, A., Ottobrini, L., Parolini, O., Bignotti, E., Calza, S., Maggi, A., Grigolato P.G. and Di Lorenzo, D. (2006) Genistein Affects Adipose Tissue Deposition in a Dose-Dependent and Gender-Specific Manner. Endocrinology, 147, 5740-5751. https://doi.org/10.1210/en.2006-0365

[9] Ae Park, S., Choi, M.S., Cho, S.Y., Seo, J.S., Jung, U.J., Kim, M.J., Sung, M.K., Park, Y.B. and Lee, M.K. (2006) Genistein and Daidzein Modulate Hepatic Glucose and Lipid Regulating Enzyme Activities in C57BL/KsJ- $d b / d b$ Mice. Life Sciences, 79, 1207-1213. https://doi.org/10.1016/j.lfs.2006.03.022

[10] Takahashi, Y., Odbayar, T.O. and Ide, T.A. (2009) Comparative Analysis of Genistein and Daidzein in Affecting Lipid Metabolism in Rat Liver. Journal of Clinical Biochemistry and Nutrition, 44, 223-230.

[11] Goodman-Gruen, D. and Kritz-Silverstein, D. (2001) Usual Dietary Isoflavone Intake Is Associated with Cardiovascular Disease Risk Factors in Postmenopausal Women. The Journal of Nutrition, 131, 1202-1206. https://doi.org/10.1093/jn/131.4.1202

[12] Zhuo, X.G., Melby, M.K. and Watanabe, S. (2004) Soy Isoflavone Intake Lowers Serum LDL Cholesterol: A Meta-Analysis of 8 Randomized Controlled Trials in Humans. The Journal of Nutrition, 134, 2395-2400. https://doi.org/10.1093/jn/134.9.2395

[13] Zhan, S. and Ho, S.C. (2005) Meta-Analysis of the Effects of Soy Protein Containing Isoflavones on the Lipid Profile. The American Journal of Clinical Nutrition, 81, 397-408. https://doi.org/10.1093/ajcn.81.2.397

[14] Taku, K., Umegaki, K., Sato, Y., Taki, Y., Endoh, K. and Watanabe, S. (2007) Soy 
Isoflavones Lower Serum Total and LDL Cholesterol in Humans: A Meta-Analysis of 11 Randomized Controlled Trials. The American Journal of Clinical Nutrition, 85, 1148-1156. https://doi.org/10.1093/ajcn/85.4.1148

[15] Chun, J., Kim, G.M., Lee, K.W., Choi, I.D., Kwon, G.H., Park, J.Y., Jeong, S.J., Kim, J.S. and Kim, J.H. (2007) Conversion of Isoflavone Glucosides to Aglycones in Soymilk by Fermentation with Lactic Acid Bacteria. Journal of Food Science, 72, M39-M44. https://doi.org/10.1111/j.1750-3841.2007.00276.x

[16] Izumi, T., Piskula, M.K., Osawa, S., Obata, A., Tobe, K., Saito, M., Kataoka, S., Kubota, Y. and Kikuchi, M. (2000) Soy Isoflavone Aglycones Are Absorbed Faster and in Higher Amounts than Their Glucosides in Humans. The Journal of Nutrition, 130, 1695-1699. https://doi.org/10.1093/jn/130.7.1695

[17] Kobayashi, M., Harada, T., Takagi, N., Tsuzuki, K., Sugawara, M. and Fukuda, M. (2012) Effects of Lactic Acid-Fermented Soymilk on Lipid Metabolism-Related Gene Expression in Rat Liver. Bioscience, Biotechnology, and Biochemistry, 76, 19-24. https://doi.org/10.1271/bbb.100354

[18] Kobayashi, M., Hirahata, R., Egusa, S. and Fukuda, M. (2012) Hypocholesterolemic Effects of Lactic Acid-Fermented Soymilk on Rats Fed a High Cholesterol Diet. $\mathrm{Nu}$ trients, 4, 1304-1316. https://doi.org/10.3390/nu4091304

[19] Hirahata, R., Kobayashi, M., Egusa, S., Sakakibara, R. and Fukuda, M. (2012) Effects of Fermented Soymilk on Lipid Metabolism in Rats Fed a High Fat Diet. Nippon Shokuhin Kagaku Kogaku Kaishi, 59, 528-532. (In Japanese)

[20] Hirahata, R., Kobayashi, M., Egusa, S., Sakakibara, R. and Fukuda, M. (2013) Lactic Fermented Soymilk Improves Hepatic Lipid Metabolism in Rats Fed a High Fat and High Cholesterol Diet. Nippon Shokuhin Kagaku Kogaku Kaishi, 60, 72-79. (In Japanese)

[21] Kobayashi, M., Sakakibara, R., Egusa, S. and Fukuda, M. (2013) Effects of Isoflavone Aglycone Ratio in Lactic Acid-Fermented Soymilk on Hepatic Lipid Metabolism in Rats Fed a High Fat and High Cholesterol Diet. Nippon Shokuhin Kagaku Kogaku Kaishi, 60, 509-515. (In Japanese)

[22] Kobayashi, M., Egusa, S. and Fukuda, M. (2014) Isoflavone and Protein Constituents of Lactic Acid-Fermented Soy Milk Combine to Prevent Dyslipidemia in Rats Fed a High Cholesterol Diet. Nutrients, 6, 5704-5723.

https://doi.org/10.3390/nu6125704

[23] Kobayashi, M., Egusa, S. and Fukuda, M. (2016) Isoflavone Aglycones and Oligopeptides in Lactic Acid-Fermented Soy Milk Differentially Regulate Lipid Metabolism-Related Gene Expression. Food and Nutrition Sciences, 7, 989-1009. https://doi.org/10.4236/fns.2016.711097

[24] Seo, M.-J., Choi, H.-S., Jeon, H.-J., Woo, M.-S. and Lee, B.-Y. (2014) Baicalein Inhibits Lipid Accumulation by Regulating Early Adipogenesis and m-TOR Signaling. Food and Chemical Toxicology, 67, 57-64. https://doi.org/10.1016/j.fct.2014.02.009

[25] Song, T.T., Hendrich, S. and Murphy, P.A. (1999) Estrogenic Activity of Glycitein, a Soy Isoflavone. Journal of Agricultural and Food Chemistry, 47, 1607-1610. https://doi.org/10.1021/jf981054j

[26] Pakalapati, G., Li, L., Gretz, N., Koch, E. and Wink, M. (2009) Influence of Red Clover (Trifolium pratense) Isoflavones on Gene and Protein Expression Profiles in Liver of Ovariectomized Rats. Phytomedicine, 16, 845-855. https://doi.org/10.1016/j.phymed.2009.03.003

[27] Mu, H., Bai, Y.H., Wang, S.T., Zhu, Z.M. and Zhang, Y.W. (2009) Research on Antioxidant Effects and Estrogenic Effect of Formononetin from Trifolium pratense 
(Red Clover). Phytomedicine, 16, 314-319. https://doi.org/10.1016/j.phymed.2008.07.005

[28] Xu, N., Zhang, L., Dong, J., Zhang, X., Chen, Y.G., Bao, B. and Liu, J. (2014) Low-Dose Diet Supplement of a Natural Flavonoid, Luteolin, Ameliorates Diet-Induced Obesity and Insulin Resistance in Mice. Molecular Nutrition \& Food Research, 58, 1258-1268. https://doi.org/10.1002/mnfr.201300830

[29] Hanaki, M., Murakami, K., Akagi, K. and Irie, K. (2016) Structural Insights into Mechanisms for Inhibiting Amyloid $\beta 42$ Aggregation by Non-Catechol-Type Flavonoids. Bioorganic \& Medicinal Chemistry, 24, 304-313. https://doi.org/10.1016/j.bmc.2015.12.021

[30] Zang, Y., Zhang, L., Igarashi, K. and Yu, C. (2015) The Anti-Obesity and Anti-Diabetic Effects of Kaempferol Glycosides from Unripe Soybean Leaves in High-Fat-Diet Mice. Food \& Function, 6, 834-841. https://doi.org/10.1039/C4FO00844H

[31] Yuan, L., Han, X., Li, W.F., Ren, D.Y and Yang, X.B. (2016) Isoorientin Prevents Hyperlipidemia and Liver Injury by Regulating Lipid Metabolism, Antioxidant Capability, and Inflammatory Cytokine Release in High-Fructose-Fed Mice. Journal of Agricultural and Food Chemistry, 64, 2682-2689.

https://doi.org/10.1021/acs.jafc.6b00290

[32] Kanashiro, A., Andrade, D.C., Kabeya, L.M., Turato, W.M., Faccioli, L.H., Uyemura, S.A. and Lucisano-Valim, Y.M. (2009) Modulatory Effects of Rutin on Biochemical and Hematological Parameters in Hypercholesterolemic Golden Syrian Hamsters. Anais da Academia Brasileira de Ciências, 81, 67-72. https://doi.org/10.1590/S0001-37652009000100009

[33] Simeonova, R., Vitcheva, V., Kondeva-Burdina, M., Krasteva, I., Manov, V. and Mitcheva, M. (2013) Hepatoprotective and Antioxidant Effects of Saponarin, Isolated from Gypsophila trichotoma Wend. On Paracetamol-Induced Liver Damage in Rats. BioMed Research International, 2013, Article ID: 757126. https://doi.org/10.1155/2013/757126

[34] Liang, Y.C., Tsai, S.H., Tsai, D.C., Lin-Shiau, S.Y. and Lin, J.K. (2001) Suppression of Inducible Cyclooxygenase and Nitric Oxide Synthase through Activation of Peroxisome Proliferator-Activated Receptor- $\gamma$ by Flavonoids in Mouse Macrophages. FEBS Letters, 496, 12-18. https://doi.org/10.1016/S0014-5793(01)02393-6

[35] Feng. X., Yu, W., Li, X., Zhou, F., Zhang, W., Shen, Q., Li, J., Zhang, C. and Shen, P. (2017) Apigenin, a Modulator of PPAR $\gamma$, Attenuates HFD-Induced NAFLD by Regulating Hepatocyte Lipid Metabolism and Oxidative Stress via Nrf2 Activation. Biochemical Pharmacology, 136, 136-149. https://doi.org/10.1016/j.bcp.2017.04.014

[36] Chanet, A., Milenkovic, D., Deval, C., Potier, M., Constans, J. and Mazur, A., Bennetau-Pelissero, C., Morand, C. and Bérard, A.M. (2012) Naringin, the Major Grapefruit Flavonoid, Specifically Affects Atherosclerosis Development in Diet-Induced Hypercholesterolemia in Mice. The Journal of Nutritional Biochemistry, 23, 469-477. https://doi.org/10.1016/j.jnutbio.2011.02.001

[37] Jung, U.J., Kim, H.J., Lee, J.S., Lee, M.K., Kim, H.O., Park, E.J., Kim, H.K., Jeong, T.S. and Choi, M.S. (2003) Naringin Supplementation Lowers Plasma Lipids and Enhances Erythrocyte Antioxidant Enzyme Activities in Hypercholesterolemic Subjects. Clinical Nutrition, 22, 561-568. https://doi.org/10.1016/S0261-5614(03)00059-1

[38] Shin, Y.W., Bok, SH., Jeong, T.S., Bae, K.H., Jeoung, N.H., Choi, M.S., Lee, S.H. and Park, Y.B. (1999) Hypocholesterolemic Effect of Naringin Associated with Hepatic 
Cholesterol Regulating Enzyme Changes in Rats. International Journal for Vitamin and Nutrition Research, 69, 341-347.

[39] Hiramitsu, M., Shimada, Y., Kuroyanagi, J., Inoue, T., Katagiri, T., Zang, L., Nishimura, Y., Nishimura, N. and Tanaka, T. (2014) Eriocitrin Ameliorates Diet-Induced Hepatic Steatosis with Activation of Mitochondrial Biogenesis. Scientific Reports, 4 , Article No. 3708. https://doi.org/10.1038/srep03708

[40] Kim, Y.W., Kim, Y.M., Yang, Y.M., Kay, H.Y., Kim, W.D., Lee, J.W., Hwang, S.J. and Kim, S.G. (2011) Inhibition of LXR $\alpha$-Dependent Steatosis and Oxidative Injury by Liquiritigenin, a Licorice Flavonoid, as Mediated with Nrf2 Activation. Antioxidants \& Redox Signaling, 14, 733-745. https://doi.org/10.1089/ars.2010.3260

[41] Na, A.Y., Yang, E.J., Jeon, J.M., Ki, S.H., Song, K.S. and Lee, S. (2018) Protective Effect of Isoliquiritigenin against Ethanol-Induced Hepatic Steatosis by Regulating the SIRT1-AMPK Pathway. Toxicological Research, 34, 23-29.

[42] Kim, Y.M., Kim, T.H., Kim, Y.W., Yang, Y.M., Ryu, D.H., Hwang, S.J., Lee, J.R., Kim, S.C. and Kim, S.G. (2010) Inhibition of Liver X Receptor- $\alpha$-Dependent Hepatic Steatosis by Isoliquiritigenin, a Licorice Antioxidant Flavonoid, as Mediated by JNK1 Inhibition. Free Radical Biology \& Medicine, 49, 1722-1734. https://doi.org/10.1016/j.freeradbiomed.2010.09.001

[43] Cunin, R., Glansdorff, N., Piérard, A. and Stalon, V. (1986) Biosynthesis and Metabolism of Arginine in Bacteria. Microbiological Reviews, 50, 314-352.

[44] Chijimatsu, T., Yamada, A., Miyaki, H., Yoshinaga, T., Murata, N., Hata, M., Abe, K., Oda, H. and Mochizuki, S. (2008) Effect of Freshwater Clam (Corbicula fluminea) Extract on Liver Function in Rats. Nippon Shokuhin Kagaku Kogaku Kaishi, 55, 63-68. (In Japanese)

[45] Sugino, T., Shirai, T., Kajimoto, Y. and Kajimoto, O. (2008) L-Ornithine Supplementation Attenuates Physical Fatigue in Healthy Volunteers by Modulating Lipid and Amino Acid Metabolism. Nutrition Research, 28, 738-743. https://doi.org/10.1016/j.nutres.2008.08.008

[46] Shi, H.P., Fishel, R.S. and Efron, D.T. (2002) Effect of Supplemental Ornithine on Wound Healing. Journal of Surgical Research, 106, 299-302. https://doi.org/10.1006/jsre.2002.6471

[47] Gupta, V.K., et al. (2013) Restoring Polyamines Protects from Age-Induced Memory Impairment in an Autophagy-Dependent Manner. Nature Neuroscience, 16, 1453-1460. https://doi.org/10.1038/nn.3512

[48] Minois, N. (2014) Molecular Basis of the "Anti-Aging" Effect of Spermidine and Other Natural Polyamine-A Mini-Review. Gerontology, 60, 319-326. https://doi.org/10.1159/000356748

[49] Kunkee, R.E. (1974) Malo-Lactic Fermentation and Winemaking. Advances in Chemistry, 137, 151-170.

[50] Da Conceicao Neta, E.R., Johanningsmeier, S.D. and McFeeters, R.F. (2007) The Chemistry and Physiology of Sour Taste-A Review. Journal of Food Science, 72, R33-R38. https://doi.org/10.1111/j.1750-3841.2007.00282.x 